\title{
The Role of EFL Teacher's Talk and Identity in Iranian Classroom Context
}

\author{
Afsaneh Alijani \\ Department of English Language, Ayatollah Amoli Branch, Islamic Azad University, Amol, Iran \\ Hamed Barjesteh \\ Department of English Language, Ayatollah Amoli Branch, Islamic Azad University, Amol, Iran
}

\begin{abstract}
Identity is a comprehensive and complicated concept in the process of language teaching and learning. The present study attempted to examine the effect of teachers' talk and identity in the classroom context on EFL learners' achievements. The Conversation Analysis (CA) approach was applied to gather and analyze naturally-occurring spoken interaction. The teachers' interactions with their learners were audiorecorded and analyzed in terms of the IRF cycle (Initiation-Response-Feedback), turn-taking and renovate. The findings indicated that the plenty of interaction was assembled and retained through dissymmetrical and privileged relations. The teacher identified, and regulated most of the social actions that happened in the classroom context, most of which were also completely designed on a goal-oriented basis .It was concluded that it is time to re-assert the role of teacher as a dominant individual who controls learning inside and outside the classroom; educators and teachers should develop an instructional design that focuses on incorporating active learning and student-centered pedagogy into the traditional lecture-based courses.
\end{abstract}

Index Terms - classroom context, identity, teachers' identity, teachers' interaction, student-centered learning

\section{INTRODUCTION}

Identity is considered as one of the fundamental concepts in language learning and teaching. In last two decades, there was an increasing interest among scholars in identity. According to Schwartz (2001), although, identity comprises varied and complex meanings and interpretations involving those associating with people's internal systems, it has become a powerful issue. Historically, identity was evolved from the interpretation of human behavior. For understanding and digesting this concept, it is important to define it. In defining identity as a noticeable construct in language teaching, the central issue is to concern the fundamental question 'who am I?' and 'who are you?'. Such questions could involve a self-concept originating from an introspective reflection (Who am I?).Also, it can be a response from an external question from another person or group. Basically, this realm involves a more social perspective. As Gill (2000) points out that identity evolves as individuals take part in social life or as they act as members of a group. According to Cote and Levine (2002), identity is defined as "the consequence of external, social, political, and economic forces" (p. 9).

The view of teacher identity focuses the individual features of the teacher and how these are mingled with the possibilities supplied in the institutional and pedagogical identity of teacher and the processes of a particular field, as these are achieved in unique situations of teaching. The aspects of the identity of the teacher in language teaching are evolved from a literature review on identity and expressed in terms of the foundational and progressive competences needed for teaching of the language, as described by experienced from teacher statements (Pennington et al. 2016). In the present study, the identity of teacher is taken into account. It is going to review the concepts of identity and teacher identity, how these relate to the particular attributes of language teaching, and how the identity of teacher can be expanded through participation and teacher education. Teacher-learning contains "not only discovering more about the techniques and education of language teaching but also what it means to be a language teacher. Identity plays a crucial role in instruction, as juxtaposed with other careers" (Singh and Richards, 2006, p.155).

Being a teacher meaning can be mainly indicated by what establishes the visible and invisible scopes of work and life. The visible domain is related to what teachers do in the classroom context (classroom interaction, materials design, assessment and so on) and the invisible domain is associated with personal phenomena such as emotions, beliefs, cognition and so on. The personal (self-) and the external (social) inform and complement each other (Borg, 2009). The knowledge attained in classrooms, the concept of what instruction is about as well as the quantity to referee pictures of good and bad instructors, prepare proposed teachers to construct a pretended concept of what makes a teacher. This origin of factual knowledge is strengthened with qualified knowledge as they enroll in a teacher education program (Johnson, 2009). In summary, teacher identity is viewed as 'relational, negotiated, constructed, enacted, transforming and transitional' (Miller, 2008, p. 174). The main purpose of the present study is to examine the teachers' external and internal identity based on narrative inquiry. But before dealing with this concept, the theoretical framework of identity and teacher identity are taken into account. 


\section{REVIEW OF THE RELATED LITERATURE}

\section{The Concept of Identity}

The notion of identity undoubtedly appoints the meanings encompassing the person, as well as her/his skill as a member of a public association. Discussing about identity in individual items involves psychological, affective, and intellectual concepts. On the contrary, the sociological aspect comprises epithets such as gender, race, age, or community as well as social, classical and educational elements. Even though these two attitudes have been approximated separately by psychologists and sociologists, it is hard to determine exactly where the person extends and the social starts; so that 'the target must be on the procedure of their common structure' (Wenger, 1999, p.146).Identity is a term that has historically evolved from the interpretation of human behavior. It has also been delineated as an external or internal aspect. Sociologists assert that identity is "the consequence of independent, general, governmental, and financial efforts" (Cote \& Levine, 2002, p. 9) while, moreover, psychologists discuss that it interests the self'internal, personal, willful possible' (ibid). Both grounds have provided to accepting the meaning and foundations of identity. According to Miller (2009, p.178), identity is 'a complex and multiple individual and social phenomenon, which has critical links to power and legitimacy'.

According to Cooley (1902), the concept of the 'looking glass', seeing the formation of the self as "part of a compulsory, training progress by which principles, perspectives, behavior, aspects and identities are increased over time" (cited in Day, 2008, p. 17). This explanation discriminates with the argument that identity is a method related to group cooperation in which language and knowledge play a main role (Mead, 1934, cited in Day, 2008). To prove this argument, he introduced three central tenets: personality (mind), interaction (self) and social structure (society).

Identity involves several proportions based on the postulation that is reflected in the work of Erickson (1968). Erickson (cited in Cote \& Levine, 2002, p. 15) involves: 'ego identity (a sense of temporal-spatial continuity); the individual aspect (a behavioral and feature collection that discriminates personals); and the social scope (the roles played within a group)'. According to Erickson, all three of these dimensions together develop a regular personality identity, preparing behavior and individuality constant. This recent hypothetical outlook points identity as a complicated quantity with both emotional and sociological features.

\section{The concept of Teacher Identity (TI)}

Being a teacher is interpreted into two domains: visible and invisible. The first one is related to the activities which are carried out in the classroom context by teachers such as classroom interaction, assessment, task implementation and the second one is associated with the personal phenomena such cognitions, beliefs, sensations. These two areas seem to be described in the long standing contest conceptualizing identity as a subjective (the self) or extrinsic (social) circumstance, as shortly investigated in the preceding part. The external factor indicates macro-cultural structures affectionately connected to the experienced performances contracted in performing their roles. The individual and the social instruct and supplement each other. The interior figures composed by teachers, which are investigated main in the development of teacher identity, come from a lengthy process which begins in their involvements as learners (Borg, 2004). Throughout this time, for example, qualified assumptions, inspirations, feelings, and essence opinions about training and learning appear. The knowledge obtained in classrooms, the notion of what teaching is about as well as the capacity to compare patterns of good and bad teachers, allow expected teachers to constitute a predefined view of what constructs a teacher. Teachers have been reassured to revert on their practice at the distinct stages of their progresses in contemplation of discovering who they think they are (Farrel, 2015).

\section{The Review of Teacher Identity}

The consideration of teacher identity (TI) acquired developing concern in the literature of teacher education in the last decade (Clarke, 2008). The traditional view about identity showed that personal role of the teacher is considered by social positions that an individual performs in the society. The self refers to motivational factors, pedagogical and subject matter knowledge, and values while social role refers to the social recognition of others. Beijaard (1995) defined the self as representations of a person's theories, attitudes and beliefs. However, theories, attitudes or beliefs appear implanted in a person's mind, or even innately in nature, they are inseparably related to context, ability, and civilization. As a result, the teacher and teaching meanings are basically formed from teachers' mental images and the socially constructed paradigms that others assign to them.

\section{Discourse and Discourse Analysis}

Cook (1989) pointed out discourse is elaborated as "the language in use" (p. 6). Brown and Yule (1983) defined discourse analysis as "the examination of language we utilize" (p. 1). In other words, discourse analysis is associated with considering of the affinity between language and the situations in which it is applied. It includes examining both language function and language form and involves the analysis of both written texts and spoken interaction. It determines linguistic characteristics that attribute various genres as well as cultural and social components that assist in our investigation and understanding of various texts and kinds of speech.

Discourse analysis assists us to realize how people apply actual language, as contested to studying artificially created sentences. Therefore, it is urgent interest to language teachers because it is required to regard how people apply language when we design and prepare materials of teaching, or when we engage learners in activities and exercises aimed at making them proficient users of their target language, or when we assess a piece of commercially published material before making decisions to apply it (McCarthy, 2002). 
Since spoken language is "the medium by which much teaching occurs and in which learners demonstrate to teachers much of what they have acquired" (Cazden,1987, cited from Wittrock,1988, p. 31), the application of discourse analysis to L2 teaching and learning can indicate much about how teachers can enhance their teaching practices by researching actual language use in the classroom, and how learners can acquire language through exposure to different types of discourse. Classroom discourse analysis is as a dimension of classroom process investigation, which is one way for teachers to check both the quality and quantity of learners' output. Nunan has mentioned that "If we want to enrich our understanding of language learning and teaching, it is required to pass time looking in classroom" (Nunan, 1989, p.76). Based on investigators' views of communicative teaching, "failed communication is a joint responsibility and not the fault of speaker or listeners. Similarly, successful communication is an accomplishment jointly achieved and acknowledged" (Richards \& Rodgers, 2001, p. 77).

Talk and Identity

As Benwell and Stokoe (2006) indicated some approaches which have concentrated on the discourse and identity analysis. According to social constructionist approach, identity "is a public phenomenon, a performance or construction that is investigated by other people. This construction happens in discourse and other social and embodied conduct..." (p. 4). This reverses a great modification from precedent identity views as an internal cognitive account to a more postmodern approach that seems at it in terms of semiotic and discursive issues, in spite of the claim that appears when some scholars and investigators view identity as represented in discourse while others argue that it is dynamically constituted in it. Discourse is applied by people to achieve social actions, which indicate how we talk, who we are, what we say or what we mean. That social construction of identity is "skillful, contend, attributed, opposed, instructed and arranged in discourse"(ibid, p. 4). Some other techniques such as critical social psychology, distributing theory or psychoanalysis also analyze the discursive construction of identity.

\section{MethodOLOGY}

\section{Participants}

In the present study, two English vocabulary learning classes were examined. The participants were divided into two groups: teachers and learners. A novice teacher and an experienced one were selected for this study. Both teachers were male. The novice teacher was 22 years old and his experience was about 1 year. Unlike the novice teacher, an experienced teacher was 38 years old and his teaching experience was about 12 years old. The setting of discourse indicates an image a group of ten learners in two classes ( 6 females and 4 males). Each class comprised 5 learners. The learners are attending English lessons for personal purposes. The leaners' age ranged from 13 to 16 . The class environment was friendly among language learners and the teachers. The learners' proficiency level was intermediate.

Instruments

Ten words were selected and applied in the present study to examine in the classroom context. These words were taught by both novice and experienced teachers based on interaction, question, answer, and explanation.

\section{Method and Data Collection}

Conversion analysis (CA) is viewed as a methodology that concentrates its interest on the naturally-occurring interaction interpretation. In the present section, there is a brief explanation about using of this approach, which was established by Sacks and Schegloff. They pointed out "realistic observational method that could cause with the factors of social action harshly, empirically and formally" (Schegloff \& Sacks, 1973, p. 289). Although CA isn't associated with conversation alone, it is basically related to depicting all functions modes of talk in interaction and other forms of conduct such as gesture, facial expressions, body language and so forth (Schegloff, Koshik, Jacoby \& Olsher, 2002).

The data was collected and transcribed outside of the classroom talk in a Persian context, was applied for understanding the identity of professional teacher. Both professional English language teachers and recruit were audiorecorded while they were teaching English and specially vocabulary to two mixed-intermediate classes. A two-hour lesson in detail was transcribed ensuing the transcription system adapted from van Lier (1988) and Johnson (1995).

As Pike (1967) pointed out that the emic point of view studies behavior from inside the system. There were no prior or predetermined research questions or interest, the analysis emerges from internal. The analysis of the present study is completely data-driven and provides from any interactional characteristic that attracts the analysts' attention. Six extracts of classroom talk were selected, examined and analyzed at a micro-level of interpretation in an emic-empirical perspective in terms of the IRF/E cycle (Initiation-Response-Feedback/Evaluation), turn-taking and repair. No predetermined criteria regarding the extracts' number or length were identified. For instance, exclusively, they were decided by the analysts.

The teachers attempted to provide a casual and non-aggressive tone of voice, classroom management and rearrangement for instance, describe a highly stimulating atmosphere that enhances and makes occasions for language learning. In other words, the students revealed a high degree of learning engagement.

\section{FINDING}


In this section, the interactional flow of the lesson was analyzed based on the IRF/E cycle perspective, the organization of turn-taking and reconstruction. Also, the arrangement and inferences of such a nested institutional process were analyzed at a micro-level of investigation.

\section{The IRF Cycle}

The IRF cycle is called Initiation-Response-Feedback and it was broadly attracted a lot of research since Bellack, Kliebard, Hyman, (1966) initial classroom structure determination depended on three distinguished swap patterns: asking (demand), answer and reply. It was determined as a basic cycle of teaching, specifically resolving and approximately principal in the context of language. Sinclair and Coulthard (1975) specifically illustrated it as a significant interactional approach or "a more complicated discourse model of classroom interaction" (Walsh, 2006, p. 41). Kasper (2001) has been accepted or criticized the IRF cycle. He argued that students could advantage more if teachers supply some chances for them to interact.

Extract 1 describes the performance of the experienced teacher and the participant and it was utilized as a tool to determine how this model of teaching and learning identified most of the actions of the classroom and what the teacher does in the classroom.

Extract 1 (turns $01-09$ )

01 Teacher: Oh look, what's this word?

02 Learner 1: ... actor.

03 Teacher: All right. This is a noun or adjective, Maryam? Come on, please.

04 Learner 2: Adjective.

05Teacher: An adjective?

06Learner 2: (4).

07 Teacher: Adjective?

08 Learner 2: No, I think it is noun.

09 Teacher: Correct. (Laughing)

Extract 1 initiated with a sample of the IRF/E interactional pattern. The teacher judges the utterances of a learner in a prior turn as correct (turn 02). She answered with a little pause. In the second part, the teacher asked a question with a high intonation. (turn 03) and initiated another interactional cycle by verbally proposing either Maryam as the next speaker.

The instructor applies a vocabulary channel, 'come on' (turn 03), to invite learners to change talk.as. It is an approach to make a friendly atmosphere and to get a genuine learner's 2 answer. This is absolutely accepted by Maryam who decides to reply cooperatively (turn 08). The identified learner was guided by implicit instruction with teacher's different tone. Ultimately, in the (turn 9), the teacher provided feedback/evaluation again. What identity image could an analyst get from this interactional classroom chunk? However, dissimilar feasibilities for tracking, some clarification could be produced from extract's 1 image of irregular ability associations. The teacher inevitably assisted the learner to find the answer.

Extract 2 also begins with the performance of the novice teacher and the participant and it was applied as a tool to determine what the teacher does and how this model of teaching and learning identified most of the classroom behaviors.

Extract 2 (turns 010 - 018)

010 Teacher: The third word, what is the third word?

011 Learner 3: ...Amoral.

012 Teacher: Amoral, right. So, what is the function of amoral?

013 Learner 3: ((4))

014 Teacher: Functions like as noun, verb, adjective, and so on. So, [tell me]

015 Learner 3: noun?

016 Teacher: Amoral is a noun? Is it right?

017 Learner 3: I think (0.2) =

018 Teacher: You think. No, this is not an adjective. This is noun.

Extract 2 starts learner 3 responding to a question asked by the teacher (turns 10). The turns have been arranged based on the topic. After asking the question and answering the question with pause, the evaluation of the answer was "right" (turn 12). The teacher continued and asked another question about the function of the word. After fairly long silence, the learner could not answer the question and the teacher attempted to help the learner implicitly. But, the learner could not find the answer of the question and ultimately, the teacher answered the question explicitly (turn 18). This extract like as the previous one included two or three IRF/E mode, but in the former part, the learner answered the question implicitly. In the second part, the learner got the answer explicitly.

\section{Turn-taking Organization}

The considerations of turn-taking basis emerged in the early steps of CA in the explorations by Sacks and Schegloff (1973). Generally, it is defined as conversions that discourse participants displace in organized form in a mainly analytical turn-by-turn ground. Normative principles of interaction were established that every party supervens "by reference to one-party at a time, in contempt of they are recognized over intentionally concurring talk..." (Schegloff, 
2000, p. 48). The language classroom context is necessarily specified by the turn-taking organization. One speaking at a time appears institutionally nested and their influences on interaction are certainly effective.

Extract 3 is applied to demonstrate some features that were specified in the current analysis.

Extract 3: (turns 019-026)

019 Teacher: The aim of this session is to teach new word and new expressions that we need -for communicating with others yes?

020 Learner 3: Yes, yes.

021 Teacher: Thank you very much. The first word is

022 Learner 3: er [Apolitical]

023 Teacher: [A political] or apolitical?

024 Learner 3: Apolitical. er (0.1) This is right, teacher?

025 Teacher: Apolitical- yes. Do you like politics?

026 Learner 3: No.

Extract 3startsintroducing the topic of the lesson by the teacher as a turn taker. An experienced teacher introduced the topic and ask a question (turn 019). In the next turn, learner 3 answered to the learner. In the turn 024, the learner took the turn and asked a teacher a question. The teacher in the next turn answered to the learner (turn 025).

Extract 4 (turns 027 -033)

027 Teacher: The meaning of astonishing is

028 Learner 9: er (0.3) terrible.

029 Teacher: No, no. This is no right.

030 Learner 9: er. I don't know.

031 Teacher: Doing thing in the best form and [interesting]

032 Learner 9: [interesting] and attractive

033 Teacher: well done.

Extract 4 also begins with asking the meaning of the word by the novice teacher as a turn taker (turn 027). The learner starts with a hesitant discourse marker ' $e r$ ' and a 0.3 second pause (turn 028) and provided a wrong answer. In the next turn, the teacher did not confirm his answer (Turn 029). In turn 30, the learner could not find the right answer. After providing explanation, the learner found the meaning of the word (Turn 032). The teacher provided the confirmed his answer (Turn 033).

\section{Extract 5 (turn 034 - 044)}

034 Learner 4: er (0.2)... This word can relate to the [person's feature].

035 Teacher: [person's feature]. This sentence is right?

036 Learner 4: (0.3) I think... er... yes.

037 Teacher: You mean that this sentence does not have any problem.

038 Learner 4: er (0.2)... yes.

039 Learner 1: No, I think there is [a problem] in this sentence.

040 Teacher: a problem. What is this?

041 Learner 1: grammar

042 Teacher: right. (CORrect). [laughing] Which part?

043 Learner 1: [laughing] Dear teacher, this word can be related to the person's feature. This is a passive form.

044 Teacher: Oh, very well. Thank you.

Learner 4initiated with a hesitant discourse marker ' $e r$ ' followed by a 0.2 first pause in presenting the information about the specific word (turn 34). He produced the wrong sentence. Turns 34 and 35were overlapped with the clause [person's feature]. The learner attempted to correct the sentence in terms of grammar; but he couldn't provide a correct form (turn 36). In this turn, the learner had 3 second pauses. In the turn 23, tis hesitation continued 2 second pauses. At last, another learner attempted to specify and correct the error (turns 041 and 043). This extract indicated self-initiated other repair form.

It can be stated that in the upper extract, both teacher-student and student-student repairs took place. In turn 037, the teacher attempted to correct the learners implicitly and in turn 039, learner 1 attempted to correct the sentence.

\section{Extract 6(turns 045 - 048)}

045 Learner 6: er (0.1)...The meaning of Outstanding is clear.

046 Teacher: Is it right?

047 Learner 6: Oh, no. It means er important.

048 Teacher: That's great.

Learner 6 started a hesitant discourse marker ' $e r$ ' followed by a 0.1 first pause in giving the meaning of the word (significant) (turn 045).In this turn, the learner provided a wrong. In the second effort, that learner provided the right meaning of this word (turn 047).Unlike the previous extract, this extract indicated self-initiated self-repair form.

According to Van Lier (1988), however, generally, repair has been classified as one of the most frequent actions that teachers perform in the language classrooms, its classification differs based on the pedagogical focus. The data revealed that two separate roles played by the teacher and other learners were related to repair as a varied approach that involves 
error correction (turn 035), confirmation check (turns 35 and 41). Seedhouse (2004) revealed that negative evaluation is hardly showed by the interpretation of classroom data that proved while looking at extract 3 in this study.

\section{CONCLUSION AND DisCUSSION}

Related pictures of the way the professional identities of teacher are rebuilt and formed throughout their interactions were indicated based on the classroom talk examination in the present research. A numeral of unbalanced interplay was presented to empower the teacher's role as dominant over learners. Both teachers posed the questions, pre-allocate turns and held the floor to make sure pedagogic control. An interaction model depended upon a teacher-learner format is common without structures of student-student alteration, for instance. Ordinarily, learners react to the explorations of teachers and barely select a more dedicated performance. However, the cycle of IRF is argued to be a feature of a 'conventional' teacher-centered classroom context, it was a common educational progress in the context of the present study. The teacher supposes half of the conversational shifts which are depended on a question-answer subsequent system. Repair considers the error correction form basically with no clear purpose to 'let some of them go' while in some other positions some mistakes are classified as repairable by the teacher. Some other forms of repair such as simplification inquiry or validation test arose sporadically and their impacts on education sound to be more advantage than the errors adjustment.

In the context of this study, there are five areas in which the teacher-centeredness of the classroom is distinctly identified: the equivalence of capability, the action of substance, the teachers' role, the accountability of learning, and the aim and processes of judgment. It is concluded that it is time to advocate the role of teacher as a dominant personal who controls learning inner and outer the classroom. Being learner-centered does not mean rejecting traditional teaching methods. According to Sawant et al. (2015), teachers and educators should develop an instructional design that focuses on incorporating active learning and student-centered pedagogy into the traditional lecture-based courses. These changes will accelerate enhancement in learners' perspectives and attainment. Albeit the changes to be carried out may require a significant time engagement at first, it will necessarily be a kind of contribution because it will not require excess attempt to teach the corrected ideal in the future and it can also contribute a catalyst for institutional reform. In contrast to teacher -centered learning, student-centered learning should be developed in educational settings in which teachers give students opportunities to lead their learning activities, participate more actively in discussions, design their own learning projects, search topics that interest them, and generally contribute to the design of their own course of study. Thornburg (1995) also argues that students are essential to the classroom, just like a team member is essential to a game. Teachers should be part of the description of student-centered education, but they are not the main tendency. The students are the center, and the teacher is a person who can help small groups of learners. Teachers should act as a facilitator.

Language teachers should not only be familiar with the theoretical orientations of language teaching and learning but also be involved in developing theory themselves. In the words of Sharkey, they should be 'active readers, users, and producers of theory' (2004, p. 281). The results of this study are in line with what Richards and Rodgers summarize:

English language teaching is an occupation, which means that it is seen as a career in a field of instructional profession, it needs a specialized awareness vulgar attained through both academic study and practical experience, and it is a field of work where membership is based on entry requirements and standards. Becoming an English language teacher means becoming part of a general society of specialists with common objects, values, discourse, and procedures (2001, p. 52).

This study also offered an explanation of how identities of teachers are formulated and the consequences that may happen to teachers and learners when they are established. It demonstrated how teachers and students understandings of identity can promote teaching and learning. Regarding this point, the result of the present study is in line with what Hall.et al. (2009) discussed in his paper; although students and teachers do not always share the same understandings of identities, the teachers' identities are given eminence in school rooms. Learners should attribute to the prevalent models of identity or risk being marginalized. While there is any data shows that why teachers are not aware of this belief, one probable expression is that learners don't know the meaning of an active learner and what impact their behaviors in the class.

\section{REFERENCES}

[1] Beijaard, D. (1995). Teachers' prior experiences and actual perceptions of professional identity. Teachers and Teaching, 1 (2), 281-294.

[2] Bellack, A. A., Kliebard, H. M., Hyman, R. T. (1966). The language of the classroom. New York, Teacher's College Press.

[3] Benwell, B., \& Stokoe, E. (2006). Discourse and identity. Edinburgh: Edinburgh University Press.

[4] Borg, S. (2009). Language teacher cognition. In A. Burns \& J. C. Richards (Eds.), The Cambridge guide to second language teacher education (pp. 163-171). Cambridge: Cambridge University Press.

[5] Borg, M. (2004). The apprenticeship of observation. ELT Journal, 58 (3), 274-276.

[6] Brown, G., \& Yule, G. (1983). Discourse analysis. Cambridge: Cambridge University Press

[7] Clarke, M. (2008). Language teacher identities: Co-constructing discourse and community. Clevedon: Multilingual Matters.

[8] Cook, G. (1989). Discourse. Oxford: Oxford University Press. 
[9] Cote, J. E. \& Levin, CH. (2002). Identity formation, agency, and culture, 22, New Jersey: Lawrence Erlbaum Associate.

[10] Day, C. (2008). Committed for life? Variations in teachers' work, lives and effectiveness. Journal of Educational Change, 9(3), 243-260. http://dx.doi.org/10.1007/s10833-007-9054-6.

[11] Farrell, TSC. (2015). Promoting teacher reflection in second language education: A framework for TESOL professionals. New York: Routledge

[12] Gill, G. (2000). The dynamics of democratization. elites, civil society and the transition Process. New York: MacMillan.

[13] Hall. L., \& Johnson, A., \& Juzwik, M., \& Wortham, S., \&Mosley, M. (2009). Teacher identity in the context of literacy teaching: Three Explorations of Classroom Positioning and Interaction in Secondary Schools." Teaching and Teacher Education. Vol. 26(2). p. 234-243.

[14] Johnson, K. F. (1995). Understanding communication in second language classroom. Cambridge, Cambridge University Press.

[15] Johnson, K. (2009). Second language teacher education: A sociocultural perspective. New York: Routledge.

[16] Kasper, G. (2001). Four perspectives on L2 pragmatic development. Applied Linguistics. N 22, pp. 502-530.

[17] McCarthy, M. (2002). Discourse analysis for language teachers. Shanghai: Shanghai Foreign Language Education Press.

[18] Miller, J. (2008). Teacher identity. In A. Burns \& J. C. Richards (Eds.), The Cambridge guide to second language teacher education (p. 174). Cambridge: Cambridge University Press.

[19] Miller, J. (2009). Teacher Identity. The Cambridge Guide to Second language teacher education. New York: Cambridge University Press. 172-81.

[20] Nunan, D. (1989). Designing tasks for the communicative classroom. Cambridge: Cambridge University Press.

[21] Pennington, M., \& Richards, J. (2016). Teacher identity in language teaching: Integrating personal, contextual, and professional factors. RELC Journal, 47(1), 5-23. https://doi.org/10.1177/0033688216631219.

[22] Pike, K. (1967). Language in relation to a unified theory of the structure of human behavior. The Hague, Mouton.

[23] Richards, J. C., \& Rodgers, T. S. (2001). Approaches and methods in language teaching (2 $2^{\text {nd }}$ ed.). New York: Cambridge University Press. http://dx.doi.org/10.1017/CBO9780511667305.

[24] Sawant, Sh. P., \& Rizvi, Sh. (2015). Study of passive didactic teacher centered approach and an active student centered approach in teaching anatomy. International Journal of Anatomy and Research, v.3, 1192-97.

[25] Schegloff, E. A., \& Sacks, H. (1973).Opening up closings. Semiotic, 7,289-326.

[26] Schegloff, E. A. (2000). Overlapping talk and the organization of turn-taking for conversation. Language in Society. 29, pp. 163.

[27] Schegloff, E.A., Koshik, I., Jacoby, S. \& Olsher, D. (2002). Conversation analysis and applied linguistics. Annual Review of Applied Linguistics, 22, 3-31.

[28] Schwartz, S. J. (2001). The evolution of Eriksonian and neo-Eriksonian identity theory and research: A review and integration. Identity: An International Journal of Theory and Research, 1, 7-58.

[29] Seedhouse, P. (2004). The interactional architecture of the language classroom: A conversation analysis perspective. London, Blackwell.

[30] Sharkey, L. (2004). ESOL Teachers' knowledge of context as critical mediator in curriculum development. TESOL Quarterly. 38(2). 279-99.

[31] Singh, G., \& Richards, J. C. (2006). Teaching and learning in the language teacher education course room: a critical sociocultural perspective. RELC Journal 37(2): 149-75.

[32] Sinclair, J. M., \& Coulthard, M. (1975). Towards an analysis of discourse. Oxford, Oxford University Press.

[33] Thornburg, D.D. (1995). Welcome to the communication age. Internet Research. V.5. pp. 64-70.

[34] Van, L. (1988b). What's wrong with classroom talk? Prospect. $\mathrm{N}^{\circ} 3$, pp. 267-283.

[35] Walsh, S. (2006). Investigating Classroom Discourse. Abingdon, Roudedge.

[36] Wenger, E. (1998). Communities of practice: Learning, meaning, and identity. New York: Cambridge University Press.

[37] Wittrock, M. C. (Ed.). (1988). Handbook for teaching research ( $3^{\text {rd }}$ ed.). New York: Macmillan.

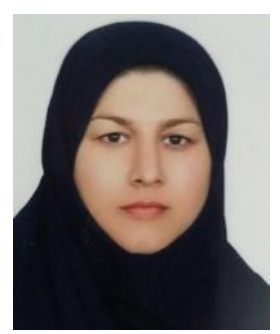

Afsaneh Alijani is a Ph.D. candidate in Ayatollah Amoli Islamic Azad University. She is an EFL teacher in Amol, Iran. She is interested in Psycholinguistics, language teaching and SLA.

Articles:

The Mind-body problem. A Alijani, H Barjesteh. Journal of Advances in English Language Teaching 5 (1), pp. 11-12 (2017)

Learning and Reflection through Collaborative Writing (2015). IJMLT

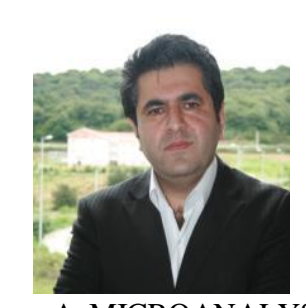

Hamed Barjesteh is an assistant professor in TEFL. He is the faculty member and the head of English language department in IAU, Ayatollah Amoli Branch. He has published many papers and presented articles in national and international conferences. He is interested in critical thinking, critical pedagogy and critical discourse analysis.

Articles:

A Synthesis of Language Learning Strategies: Current Issues, Problems and Claims Made in Learner Strategy Research. H Barjesteh, J Mukundan... - Advances in Language ..., 2014 - journals.aiac.org.au

Utilizing Reflective Journal to Raise Critical Language Awareness: A Critical Literacy Practice in a Reading Classroom. AM Yarahmadi, H Barjesteh - Modern Journal of Language ..., 2016

A MICROANALYSIS OF HINDRANCES IN WRITING AT HIGH SCHOOLS: LOOKING THROUGH THE LENS EFL TEACHERS AND LEARNERS. M Sabokrouh, H Barjesteh - Modern Journal of Language ..., 2016 